\title{
Effect of Glucagon Infusion on Renal Hemodynamics in Normal Subjects and Patients with Chronic Glomerulonephritis
}

\author{
Jiro UEMASU, Akihisa NAKAOKA, Akihide TOKUMOTO \\ and Hironaka KAWASAKI
}

\begin{abstract}
The effect of glucagon infusion $(15-20 \mathrm{ng} / \mathrm{kg} / \mathrm{min}$, for one hour) on renal hemodynamics was examined in normal subjects and in patients with chronic glomerulonephritis (CGN). In normal subjects, the glomerular filtration rate (GFR) was significantly increased by glucagon with a concomitant rise in effective renal plasma flow (ERPF) and filtration fraction (FF) (GFR/ERPF). In renal patients with a baseline GFR of above 90 $\mathrm{ml} / \mathrm{min} / \mathrm{l} / 73 \mathrm{~m}^{2}$, GFR was significantly increased in response to glucagon, without a significant rise in ERPF. The patients whose baseline GFR ranged from $40-90 \mathrm{ml} / \mathrm{min}$ had no significant increase in GFR, while ERPF rose significantly. These results suggest that the renal hemodynamic response to glucagon infusion were modified by the level of baseline GFR in patients with chronic glomerulonephritis.
\end{abstract}

Key words: Renal reserve, Glomerular filtration rate, Effective renal plasma flow

Recently, the renal functional reserve, or the amplitue of renal hemodynamics in response to a certain stimulus, has been focused upon, because it may provide valuable information concerning the stage at which to initiate therapy to retard the progression of renal failure. For such purposes, oral protein loading test (1-3), amino acid infusion (4) and dopamine infusion (5) have been made currently available. However, since these procedures may deliver different signals to the renal vasculature, it appears necessary to employ another method for more comprehensive analysis of hemodynamic alterations in renal disease.

Thus, glucagon that is known to increase renal blood flow $(6,7)$ was administered to normal subjects and patients with chronic glomerulonephritis to compare the changes of both renal hemodynamics and urinary electrolyte excretion.

\section{SUBJECTS AND METHODS}

Twenty-five subjects were included in this study. They were divided into three groups. Group I consisted of 8 normal subjects with a baseline glomerular filtration rate (GFR) of above 90 $\mathrm{ml} / \mathrm{min} / 1.73 \mathrm{~m}^{2}$ (age: $33 \pm 3 \mathrm{yrs}$ ). Group IIa consisted of 9 patients with a baseline GFR of above $90 \mathrm{ml} / \mathrm{min}$ (age: $33 \pm 4 \mathrm{yrs}$ ). Group IIb consisted of 8 patients with a baseline GFR between $40-90$ $\mathrm{ml} / \mathrm{min}$ (age: $44 \pm 5 \mathrm{yrs}$ ). The content of dietary sodium was restricted in group $\mathrm{IIb}(\mathrm{NaCl}, 6 \mathrm{~g} /$ day), but not in groups I and IIa.

Normal subjects were free of renal, hepatic, and cardiovascular diseases. The diagnosis of chronic glomerulonephritis was made based upon the patient's medical history, laboratory data and renal biopsy. The patient profiles are summarized in Table 1. All subjects gave verbal consent for this study. This study protocol was approved by the Ethics

From The Second Department of Internal Medicine, Tottori University School of Medicine, Yonago

Received for publication January 16, 1990; Accepted for publication August 28, 1990

Reprint requests should be addressed to Jiro Uemasu, MD, The Second Department of Internal Medicine,

Tottori University School of Medicine, Yonago 683, Japan 
Table 1. Patient profile of groups IIa and IIb

\begin{tabular}{lcccc}
\hline Group & Patients & Sex & Age(yr) & Renal histology \\
\hline IIa & 1 & M & 40 & - \\
& 2 & M & 18 & mesangial proliferative GN \\
& 3 & M & 20 & mesangial proliferative GN \\
& 4 & M & 17 & focal glomerular sclerosis \\
& 5 & F & 39 & mesangial proliferative GN \\
& 6 & M & 45 & mesangial proliferative GN \\
& 7 & M & 40 & mesangial proliferative GN \\
& 8 & F & 39 & mesangial proliferative GN \\
& 9 & M & 38 & \\
IIb & 1 & M & 23 & mesangial proliferative GN \\
& 2 & M & 40 & membrano-proliferative GN \\
& 3 & M & 45 & mesangial proliferative GN \\
& 4 & M & 54 & mesangial proliferative GN \\
& 5 & F & 32 & focal glomerular sclerosis \\
& 6 & F & 58 & \\
& 7 & F & 40 & focal glomerular sclerosis \\
& 8 & M & 64 & \\
\hline
\end{tabular}

GN, glomerulonephritis

Committee of the University.

After overnight fasting, all subjects drank $500 \mathrm{ml}$ of water at $9 \mathrm{AM}$. At the same time, a bolus injection of thiosulfate sodium $(4.0 \mathrm{~g})$ and paraaminohippurate $(\mathrm{PAH})(0.5 \mathrm{~g})$ was given, followed by continuous intravenous administration of both agents until $12 \mathrm{AM}$. The time period from 10 to 11 AM served as the baseline period. At 11 AM, glucagon (Novo Glucagon, Kodama Ltd., Co., Japan) was intravenously administered at a dose of $15-20 \mathrm{ng} / \mathrm{kg} / \mathrm{min}$ for one $\mathrm{h}$ (test period). At 10 $\mathrm{AM}$, the subjects were asked to completely void and thereafter, spontaneous voided urines were collected hourly for baseline and test period, respectively. Blood samples were obtained before the administration of thiosulfate sodium and PAH, and during the mid-points of the baseline period and test period. The following parameters were determined before and during the glucagon infusion. Blood glucose concentrations were measured by the peroxidase method. Blood urea nitrogen, serum albumin, creatinine, and electrolytes were determined using an auto-analyzer (SMAC II, Technicon, USA). Urinary concentrations of sodium and potassium were measured by flame photometry (IL 643, Italy). Thiosulfate and PAH concentrations in serum and urine were determined by the methods of Brun (8, 9). GFR and effective renal plasma flow (ERPF) were determined from the clearance of thiosulfate and $\mathrm{PAH}$, respectively. These values were all corrected for body surface area $\left(1.73 \mathrm{~m}^{2}\right)$. The GFR/ERPF ratio equated the filtration fraction (FF). The fractional excretion of X (FEx), expressed as percentages, was calculated as: urine $\mathrm{X} \times$ serum creatinine/serum $\mathrm{X} \times$ urine creatinine. Blood pressure and pulse rate were monitored before and during the glucagon infusion. The mean arterial pressure was calculated by adding one-third of the blood pressure to the diastolic pressure.

All values were expressed as the mean \pm SEM. Data were analyzed by one-way analysis of variance, followed by the paired or unpaired t-test as appropriate. Linear regression analysis was performed for the study of correlation. Significance was define as a $\mathrm{p}$ value of less than 0.05 .

\section{RESULTS}

Table 2 shows the changes in hematocrit value, serum albumin levels, and blood glucose concentration before and during glucagon infusion. Hematocrit level remained unchanged. Serum albumin value fell only slightly, but the fall was 
Table 2. Changes in hematocrit, serum albumin and blood glucose before and during glucagon infusion

\begin{tabular}{llll}
\hline Variable & Baseline & Glucagon & p value \\
\hline $\begin{array}{l}\text { Hematocrit (\%) } \\
\text { Serum albumin } \\
\text { (g/dl) }\end{array}$ & $40.5 \pm 0.8$ & $40.1 \pm 0.8$ & NS \\
$\begin{array}{c}\text { Blood glucose } \\
\text { (mg/dl) }\end{array}$ & $82 \pm 2$ & $130 \pm 4$ & $<0.001$ \\
\hline
\end{tabular}

All values are mean \pm SEM. NS, not significant

significant. Blood glucose concentration during the glucagon infusion rose significantly $(\mathrm{p}<0.001)$. Neither values of serum creatinine nor blood urea nitrogen changed significantly. Serum sodium and chloride concentrations remained unchanged, however the serum potassium level during glucagon infusion fell slightly.

The effects of glucagon infusion on renal hemodynamics in normal subjects and patients with chronic glomerulonephritis are summarized in Table 3. Both GFR and ERPF in normal subjects rose significantly in response to glucagon. But the increment $(25 \%)$ of the former was higher than that $(18 \%)$ of the latter and thus FF was significantly increased $(\mathrm{p}<0.05)$. In patients with a baseline GFR of above $90 \mathrm{ml} / \mathrm{min}$ (group IIa), glucagon increased GFR significantly $(p<0.05)$, but without such an effect on ERPF. FF in this group remained un- chaged. On the other hand, in patients with a baseline GFR from 40-90 ml/min, GFR was not increased significantly by glucagon infusion. Rather, ERPF rose significantly $(p<0.01)$, and thus, FF tended to fall.

The relationship between the baseline GFR and test GFR (GFR during glucagon infusion) in all subjects is shown in Fig. 1. A significant positive correlation was observed between these parameters

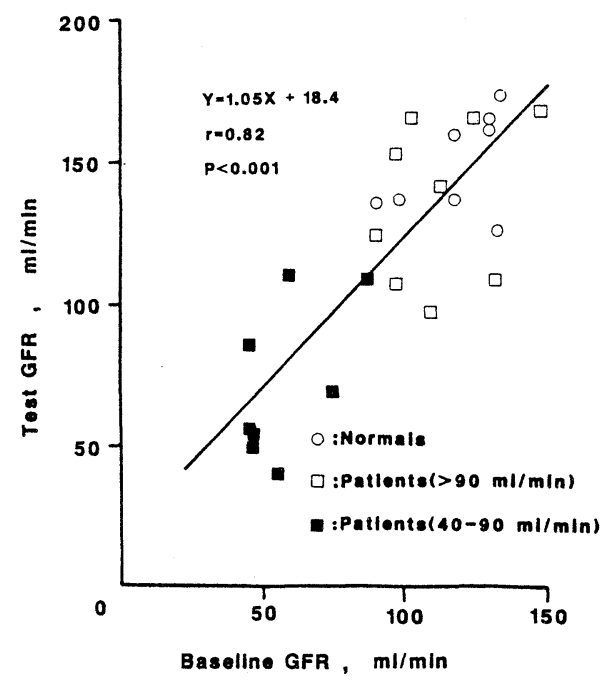

Fig. 1. Correlation between baseline glomerular filtration rate (GFR) and test GFR in all groups.

Table 3. Effect of glucagon infusion on renal hemodynamics in normal subjects and patients with chronic glomerulonephritis

\begin{tabular}{lccr}
\hline Group & Baseline & Glucagon & p value \\
\hline I. Normal subjects & & & \\
GFR, ml/min & $118 \pm 5$ & $149 \pm 6$ & $<0.01$ \\
ERPF, ml/min & $495 \pm 32$ & $586 \pm 36$ & $<0.05$ \\
FF & $0.24 \pm 0.02$ & $0.26 \pm 0.02$ & $<0.05$ \\
& & & \\
IIa. Patients (GFR $>90 \mathrm{ml} / \mathrm{min})$ & & \\
GFR & $112 \pm 6$ & $137 \pm 9$ & $<0.05$ \\
ERPF & $554 \pm 35$ & $591 \pm 36$ & $\mathrm{NS}$ \\
FF & $0.20 \pm 0.02$ & $0.21 \pm 0.01$ & $\mathrm{NS}$ \\
& & & \\
IIb. Patients (40-90 ml/min) & & & \\
GFR & $57 \pm 5$ & $72 \pm 9$ & $\mathrm{NS}$ \\
ERPF & $321 \pm 26$ & $495 \pm 57$ & $<0.01$ \\
FF & $0.19 \pm 0.02$ & $0.16 \pm 0.01$ & $\mathrm{NS}$ \\
\hline AIl
\end{tabular}

All values are mean \pm SEM. GFR, glomerular filtration rate; ERPF, effective renal plasma flow; FF, filtration fraction; NS, not significant 
Table 4. Effect of glucagon infusion on urine volume and urinary electrolyte excretion in normal subjects and patients with chronic glomerulonephritis

\begin{tabular}{|c|c|c|c|c|c|}
\hline Group & $\begin{array}{l}\mathrm{UV} \\
\mathrm{ml} / \mathrm{min}\end{array}$ & $\begin{array}{l}\mathrm{UNaV} \\
\mu \mathrm{Eq} / \mathrm{min}\end{array}$ & $\begin{array}{l}\mathrm{UKV} \\
\mu \mathrm{Eq} / \mathrm{min}\end{array}$ & $\begin{array}{r}\mathrm{FENa} \\
\%\end{array}$ & $\begin{array}{c}\text { FEK } \\
\%\end{array}$ \\
\hline \multicolumn{6}{|c|}{ I. Normal subjects } \\
\hline Baseline & $3.3 \pm 0.4$ & $541 \pm 33$ & $118 \pm 16$ & $3.7 \pm 0.3$ & $27 \pm 4$ \\
\hline Glucagon & $3.3 \pm 0.4$ & $788 \pm 62^{\mathrm{a}}$ & $105 \pm 11$ & $5.2 \pm 0.5^{\mathrm{b}}$ & $25 \pm 3$ \\
\hline \multicolumn{6}{|c|}{ IIa. Patients (GFR $>90 \mathrm{ml} / \mathrm{min}$ ) } \\
\hline Baseline & $4.0 \pm 0.2$ & $539 \pm 38$ & $102 \pm 13$ & $3.5 \pm 0.2$ & $26 \pm 3$ \\
\hline Glucagon & $3.0 \pm 0.2$ & $744 \pm 58^{\mathrm{a}}$ & $100 \pm 11$ & $5.4 \pm 0.5^{b}$ & $29 \pm 4$ \\
\hline \multicolumn{6}{|c|}{ IIb. Patients (40-90 $\mathrm{ml} / \mathrm{min})$} \\
\hline Baseline & $3.3 \pm 0.5$ & $303 \pm 56$ & $78 \pm 13$ & $4.0 \pm 1.0$ & $32 \pm 5$ \\
\hline Glucagon & $3.2 \pm 0.5$ & $520 \pm 81$ & $90 \pm 9$ & $5.5 \pm 0.6$ & $39 \pm 6^{c}$ \\
\hline
\end{tabular}

The values are mean \pm SEM. UV, urine volume; UXV, urinary $x$ excretion rate; FEx, fractional excretion of $\mathrm{x} ; \mathrm{a}, \mathrm{p}<0.001$ vs Baseline, $\mathrm{b}, \mathrm{p}<0.01$ vs Baseline, $\mathrm{c}, \mathrm{p}<0.05$ vs Baseline

$(\mathrm{r}=0.82, \mathrm{p}<0.001)$.

Data of glucagon effects on urine volume and urinary electrolytes excretion are summarized in Table 4. Both the normals and patients with a baseline GFR of above $90 \mathrm{ml} / \mathrm{min}$ demonstrated significant increases in urinary sodium excretion, but not potassium in response to glucagon infusion. In contrast, in the patients with a baseline GFR between 40 and $90 \mathrm{ml} / \mathrm{min}$, the urinary sodium excretion rate was increased by glucagon, but the increase was not significant. Rather, the fractional excretion of potassium (FEk) was significantly increased by glucagon $(p<0.05)$. There was no significant correlation between the changes of GFR and urinary sodium excretion $(\mathrm{r}=0.22$, $\mathrm{p}$ : not significant).

In all groups, glucagon had no significant influence on the pulse rate (baseline vs glucagon; $64 \pm 2$ vs $65 \pm 3$ per $\mathrm{min}$ ) or the mean arterial blood pressure (baseline vs glucagon; $89 \pm 3$ vs $87 \pm 2$ $\mathrm{mmHg}$ ).

\section{DISCUSSION}

There had been no reports regarding the effect of glucagon on renal hemodynamics in patients with renal diseases. The present study demonstrated the changes in GFR and ERPF in patients with chronic glomerulonephritis by intravenous low-dose glucagon infusion. Though we did not directly measure the plasma glucagon levels, a significant rise in the blood glucose level during exogenous infusion was regarded to reflect an elevation of plasma glucagon (10).

In this study, glucagon increased both GFR $(25 \%)$ and ERPF, and FF (8\%) rose significantly in normal subjects. In contrast, Parving et al (10) noted a $9 \%$ increase of GFR and a $9 \%$ increase of FF. These differences may be due to the variations in the study protocols. In their study, glucagon was infused at the dosage of $10 \mathrm{ng} / \mathrm{kg} / \mathrm{min}$ for $2 \mathrm{~h}$, whereas here a dosage of $15-20 \mathrm{ng} / \mathrm{kg} / \mathrm{min}$ for one $\mathrm{h}$ was used. Furthermore to promote diuresis, Parving et al gave the subjects $250 \mathrm{ml}$ of tap water every 20 min during the clearance study (10). In the present study, $500 \mathrm{ml}$ of water was given all at once prior to the experiment.

In renal patients with a baseline GFR of above $90 \mathrm{ml} / \mathrm{min}$, glucagon increased significantly GFR $(+22 \%)$ and a lesser increase of ERPF $(+6.6 \%)$. In contrast, in patients with a baseline GFR of below $90 \mathrm{ml} / \mathrm{min}$, the glucagon infusion increased GFR, but the increase was not statistically significant. However, ERPF rose significantly in response to this agent.

The reasons of distinction of renal hemodynamic changes between normals and renal patients, particularly those with a baseline GFR of below 90 $\mathrm{ml} / \mathrm{min}$, in response to glucagon infusion, might be explained as follows. Ueda et al (6) had shown 
increases in both GFR and renal blood flow, and demonstrated a selective vasodilatory effect of glucagon on renal afferent arterioles. In normal situations, glucagon may predominantly dilate the afferent anterioles. Glucagon has been demonstrated to increase plasma renin activity in man (11) and therefore it may provoke the generation of angiotensin II, that in turn constricts the efferent arterioles. Combinations of these effects of glucagon may augment glomerular transcapillary pressure, yielding a preferential elevation of GFR. In contrast, in renal patients, the glucagon effect on GFR could be diminished due to the reduced glomerular filtration surface area by pathologic changes, such as mesangial sclerosis or hyalinosis. Concomitantly, the response of the efferent arterioles to angiotensin II may be altered. In fact, we found a lesser degree of fall in ERPF in renal patients compared with that in normals to exogenous angiotensin II infusion (unpublished observations). Thus, these situations are likely to more greatly increase ERPF than GFR in patients with a reduced baseline GFR in response to glucagon. However, to verify these assumptions further, other factors such as the dietary sodium content and age in each group must be considered.

In the present study, glucagon infusion increased urinary sodium excretion in all subjects. These data were consistent with those documented by Pullman et al (12). Such a glucagon natriuresis has been regarded to be a direct tubular effect of glucagon, probably mediated by the renal prostaglandins (13), as well as an effect on renal hemodynamics. The present findings showing no significant correlation between the changes in GFR and fractional sodium excretion may lend support for the direct tubular effect of glucagon on sodium transport. In addition, it is interesting to note that greater kaliuresis rather than natriuresis was induced by glucagon in patients with a more decreased baseline GFR. These findings suggest an altered capacity of tubular electrolyte handling even in the relatively early stages of diminished renal reserve.

In summary, the present glucagon study demonstrated a higher rising rate of GFR than
ERPF in normal subjects and vice versa in renal patients with lower baseline GFR.

ACKNOWLEDGMENT: This study was supported in part by a Grant-in-Aid for Scientific Research (C01570395) from the Ministry of Education, Science and Culture of Japan.

\section{REFERENCES}

1) Bosch JP, Saccaggi A, Lauer A, Ronco C, Belledonne M, Glabman S. Renal functional reserve in humans: Effect of protein intake on glomerular filtration rate. Am J Med 75: 943, 1983.

2) Bosch JP, Lauer A, Glabman S. Short-term protein loading in assessment of patients with renal disease. Am J Med 77: 873, 1984.

3) Bosch JP, Lew S, Glabman S, Lauer A. Renal hemodynamic changes in humans: Response to protein loading in normal and diseased kidneys. Am J Med 81: 809, 1986.

4) Wee PM ter, Geerlings W, Rosman JB, Sluiter WT, van der Geest S, Donker AJM. Testing renal reserve filtration capacity with an amino acid solution. Nephron 41: 193, 1985.

5) Wee PM ter, Smit AJ, Rosman JB, Sluiter WJ, Donker AJM. Effect of intravenous infusion of low-dose dopamine on renal function in normal individuals and in patients with renal disease. Am J Nephrol 6: 42, 1986.

6) Ueda J, Nakanishi H, Miyazaki M, Abe Y. Effects of glucagon on the renal hemodynamics of dogs. Eur J Pharmacol 41: 209, 1977.

7) Farah AE. Glucagon and the circulation. Pharmacol Rev 35: 181, 1983.

8) Brun C. Sulfate determination in kidney function tests; Simple method for determination of thiosulfate in blood and urine. J Lab Clin Med 35: 152, 1950.

9) Brun C. A rapid method for the determination of paraamino-hippurate acid in kidney function tests. J Lab Clin Med 37: 955, 1951.

10) Parving $\mathrm{H}-\mathrm{H}$, Noer $\mathrm{J}$, Kehlet $\mathrm{H}$, Mogensen $\mathrm{CE}$, Svendsen PA, Heding L. The effect of short-term glucagon infusion on kidney function in normal man. Diabetologia 13: 323, 1977.

11) Fernandez-Cruz AJr, Noth RH, Heldler RG, Murlrow PJ. Glucagon stimulation of plasma renin activity in humans. J Clin Endocrinol Metab 41: 183, 1975.

12) Pullman TN, Lavender AR, Aho I. Direct effects of glucagon on renal hemodynamics and excretion of inorganic ions. Metabolism 16: 358, 1967.

13) Kirschenbaum MA, Zawada ET. The role of prostaglandins in glucagon-induced natriuresis. Clin Sci 58: 393, 1980. 